Archived version from NCDOCKS Institutional Repository http://libres.uncg.edu/ir/asu/

\title{
Appalachľan
}

B O O N E, NORT H C A R O L I A

\section{Protection As Care: Moral Reasoning And Moral Orientation Among Ethnically And Socioeconomically Diverse Older Women}

\author{
By: Emily Dakin
}

\begin{abstract}
This study examined moral reasoning among ethnically and socioeconomically diverse older women based on the care and justice moral orientations reflecting theoretical frameworks developed by Carol Gilligan and Lawrence Kohlberg, respectively. A major gap in this area of research and theory development has been the lack of examination of moral reasoning in later life. This study addressed this gap by assessing socioeconomically and ethnically diverse older women's reasoning in response to ethical dilemmas showing conflict between autonomy, representative of Kohlberg's justice orientation, and protection, representative of Gilligan's care orientation. The dilemmas used in this study came from adult protective services (APS), the U.S. system that investigates and intervenes in cases of elder abuse and neglect. Subjects were 88 African American, Latina, and Caucasian women age 60 or over from varying socioeconomic status backgrounds who participated in eight focus groups. Overall, participants favored protection over autonomy in responding to the case scenarios. Their reasoning in responding to these dilemmas reflected an ethic of care and responsibility and a recognition of the limitations of autonomy. This reasoning is highly consistent with the care orientation. Variations in the overall ethic of care and responsibility based on ethnicity and SES also are discussed.
\end{abstract}

Dakin, E. (2014). Protection as care: Moral reasoning and moral orientation among ethnically and socioeconomically diverse older women, Journal of Aging Studies. V. 28 (2014), Pages 44-56, https:// doi.org/10.1016/i.jaging.2013.12.001. Publisher version of record available at: http://www.sciencedirect.com/ science/article/pii/S0890406513000753 


\title{
Protection as care: Moral reasoning and moral orientation among ethnically and socioeconomically diverse older women
}

\author{
Emily Dakin* \\ Colorado State University School of Social Work, 1586 Campus Delivery, Fort Collins, CO 80523-1586, United States
}

Keywords:

Moral reasoning

Moral orientation

Moral development

Older women

Ethnicity

Socioeconomic status

\begin{abstract}
A B S T R A C T
This study examined moral reasoning among ethnically and socioeconomically diverse older women based on the care and justice moral orientations reflecting theoretical frameworks developed by Carol Gilligan and Lawrence Kohlberg, respectively. A major gap in this area of research and theory development has been the lack of examination of moral reasoning in later life. This study addressed this gap by assessing socioeconomically and ethnically diverse older women's reasoning in response to ethical dilemmas showing conflict between autonomy, representative of Kohlberg's justice orientation, and protection, representative of Gilligan's care orientation. The dilemmas used in this study came from adult protective services (APS), the U.S. system that investigates and intervenes in cases of elder abuse and neglect. Subjects were 88 African American, Latina, and Caucasian women age 60 or over from varying socioeconomic status backgrounds who participated in eight focus groups. Overall, participants favored protection over autonomy in responding to the case scenarios. Their reasoning in responding to these dilemmas reflected an ethic of care and responsibility and a recognition of the limitations of autonomy. This reasoning is highly consistent with the care orientation. Variations in the overall ethic of care and responsibility based on ethnicity and SES also are discussed.
\end{abstract}

(c) 2013 Published by Elsevier Inc.

\section{Introduction}

A rich body of research on moral reasoning has developed over the latter half of the 20th century, continuing to the present time. Lawrence Kohlberg, who created the first fully articulated and most influential theory of moral development, held that cognitive and moral reasoning develop in tandem, with higher levels of moral reasoning emerging as an outgrowth of abstract and logical reasoning abilities (Reimer, Paolitto, \& Hersh, 1990). Kohlberg's theory describes the structure and development of justice reasoning from childhood into adulthood, a trajectory that was posited to involve a culturally universal and invariant sequence of six stages within three broader levels of moral reasoning (Kohlberg, 1973; Kohlberg \& Hersh, 1977; Kohlberg \& Ryncarz, 1990; Levine, Kohlberg, \& Hewer, 1985). As moral reasoning develops, interpersonal considerations in moral reasoning become subordinated to an increasing emphasis on

\footnotetext{
* Tel.: +1 9704912565.

E-mail address: Emily.Dakin@colostate.edu.
}

universal principles of justice, with a focus on equality, human rights, and respect for the individual (Gump, Baker, \& Roll, 2000; Kohlberg \& Ryncarz, 1990; Levine et al., 1985).

Carol Gilligan proposed an alternate theory of female moral reasoning development based on criticism of gender bias within Kohlberg's theory (Gilligan, 1977, 1982). This theory specifies a distinct female moral language in which the primary moral imperative is the "obligation to exercise care and avoid hurt. The infliction of hurt is considered selfish and immoral in its reflection of unconcern, while the expression of care is seen as the fulfillment of moral responsibility" (Gilligan, 1977, p. 12). Gilligan's model for female moral development describes three moral reasoning levels with two transitional stages separating the levels. Moral reasoning at the first level is focused on the needs and survival of the individual self. At the second level, moral goodness is equated with self-sacrifice, and we see a conventional understanding of femininity that defines one's worth in terms of caring for and protecting others. In the third level, the orientation to self-sacrifice is subordinated to considerations of responsibility, caring, and the obligation not 
to hurt, which are directed not only towards others, but also towards the self. At this stage, truthfulness in acknowledging one's own needs changes from being viewed as selfish, as it is seen in the second level, to having connotations of honesty, fairness, and acceptance of personal responsibility (Gilligan, 1977). Both Kohlberg's and Gilligan's theories can be understood more fully when contrasted with one another; the former reflects an individual-based morality of abstract principles of justice and rights from a separate and autonomous perspective, and the latter reflects a relationship-based morality based on interpersonal considerations of caring and responsibility.

Despite Gilligan's contention, most research fails to find a statistically significant gender difference in stage using Kohlberg's theory (e.g., Maqsud, 1980; Murphy \& Gilligan, 1980; Pratt, Golding, Hunter, \& Sampson, 1988; Walker, 1984; Wilson, 1995; Zeidner \& Nevo, 1987). However, a different way to look at moral reasoning is through the lens of moral orientation, as opposed to stage of moral development. Moral orientation refers to an individual's preferred moral reasoning style, and it is different from the concept of staging. For example, someone could score at a high level on an assessment of Kohlberg's stages, but still have a preference or orientation towards the care perspective of moral reasoning described by Gilligan, or vice versa.

\section{Gender and moral orientation}

Studies (Gilligan \& Attanucci, 1988; Lyons, 1983; Pratt et al., 1988; Walker, 1989) employing a methodology in which participants respond to real-life dilemmas that they themselves had chosen have found men to favor justice reasoning, and women to favor care reasoning. However, it is likely that this is due to females being more likely to select personal dilemmas, which have been shown to elicit care reasoning, and males being more likely to select impersonal dilemmas, which have been shown to elicit justice reasoning (Pratt et al., 1988; Walker, 1989). Studies using hypothetical dilemmas-in other words, studies in which all participants have the same dilemmas-have found no gender differences in justice reasoning (Gump et al., 2000; Pratt et al., 1988; Smetana, Killen, \& Turiel, 1991; Walker, 1989; Weisz \& Black, 2002; Wilson, 1995).

Although the preponderance of evidence does not suggest gender differences in justice reasoning, there is some evidence that females may be more likely than males to utilize care reasoning. Several studies found a greater use of care reasoning among females than males in samples with African American 7th grade youth (Weisz \& Black, 2002), Mexican American and Anglo American college students (Gump et al., 2000), and nurses (Wilson, 1995). These findings of lack of gender differences in justice reasoning and partial support for gender differences in care reasoning support the contention by Gump et al. (2000) that justice and care reasoning may operate independently of one another.

\section{Critiques of Gilligan's theoretical framework}

A variety of strong criticisms have been launched against Gilligan's theoretical framework over the past 30 years. Some of these critiques stem from the failure, noted above, of most research to find gender differences in stage using Kohlberg's theory or in justice reasoning when responding to hypothetical dilemmas. Walker's (1984, 1989) studies are particularly strong examples of this line of criticism. Gilligan's research has been strongly critiqued on various methodological grounds. For example, her critics allege that in her anecdotal style of reporting findings, she selectively presents data that support her pre-existing hypotheses (Broughton, 1983; Nails, 1983; Sommers, 1995). She has also been criticized for claiming gender differences in moral reasoning based on research with female-only samples (Auerbach, Blum, Smith, \& Williams, 1985; Kerber, 1986; Sommers, 1995).

Scholars have additionally criticized Gilligan for implying a biological basis for any gender differences in moral reasoning while ignoring potential socially-based causes of gender differences, such as subordinate social status (Auerbach et al., 1985; Kerber, 1986; Tronto, 1987). A related critique is that Gilligan overemphasizes the significance of gender in moral reasoning while ignoring cultural characteristics such as ethnicity or socioeconomic status that could impact moral reasoning (Auerbach et al., 1985; Contratto, 1994; Nicholson, 1983; Tronto, 1987). If subordinate social status is the critical variable underlying care reasoning, we might predict this reasoning to predominate in a variety of groups (e.g., women, racial and ethnic minorities, or people of lower socioeconomic status) with lower social status, as opposed to only in women (Tronto, 1987). Finally, a specifically feminist critique of Gilligan's theoretical framework is that it reinforces simplistic, romanticized, and old-fashioned stereotypes of men being the rational sex and women being the feeling sex that inadvertently further oppress women (Kerber, 1986; Nails, 1983; Sommers, 1995).

\section{Culture and moral orientation}

In response to the critique that cultural factors were being ignored in moral reasoning research, from the 1990s on there has been an increasing emphasis on research examining the role that culture plays in shaping moral reasoning. In this research, various aspects of culture are explored, including international differences in moral orientation, research on moral orientation in the United States with explicit attention paid to ethnicity, and research examining differences in moral orientation based on socioeconomic status (SES).

\section{International research and socioeconomic status}

Research by Miller and Bersoff (1992) and Miller, Bersoff, and Harwood (1990) examined the role of culture by comparing differences in moral judgment among children and adults in India and the United States. Both studies supported the importance of culture, as opposed to gender, in explaining the origins of moral reasoning; in fact, neither study supported Gilligan's claims that women are more likely than men to prioritize interpersonal responsiveness and care over justice considerations. Miller and Bersoff (1992) found that, in dilemmas that present conflict between justice and interpersonal considerations, Indians prioritized interpersonal considerations, whereas Americans prioritized justice considerations. Miller et al. (1990) found views of social responsibility and morality to be culturally-based, with Indians viewing a broader range of social responsibilities in moral terms than Americans. 
The authors of both studies hypothesized that Indians possess a greater sense of responsibility to the larger social whole than do Americans. In contrast, the view of the autonomous individual as the fundamental social unit in American morality was hypothesized to lead to the emphasis on independence, privacy, liberty, rights, and individuality as core Western values.

An interesting additional feature of both studies was their examination of the impact of SES on moral judgment. Although Miller and Bersoff (1992) found little evidence of differences between high SES and middle SES Hindu Indians in moral reasoning, Miller et al. (1990) found evidence of a somewhat greater orientation towards autonomy and individualism among middle-class than lower-class Hindu Indians. Furthermore, Walker (1984) conducted a metaanalysis of research comparing men's and women's moral reasoning using Kohlberg's stage model. This meta-analysis found that studies reporting gender differences in moral reasoning were confounded by SES differences between the men and women subjects, suggesting the significance of SES in moral reasoning.

\section{Moral orientation research in the United States with explicit attention paid to ethnicity}

As noted earlier, ethnicity was largely ignored in early moral orientation research, however more recently it has been given explicit attention. For example, a rich body of research examines moral reasoning and moral orientation among African Americans. Ward (1995) proposes that traditional African American communal attitudes support the development of an ethic of care among African American young people. Similarly, research supports the proposed construct of an Afrocultural orientation with spirituality, communalism, and affect as its central, defining features (Jagers \& Mock, 1993). Research by Woods and Jagers (2003) found an Afrocultural orientation to be predictive of higher levels of moral reasoning based on Gibb's stage model of moral development (Gibbs, Basinger, \& Fuller, 1992). Finally, Weisz and Black (2002) examined African American youth responses to hypothetical dating dilemmas. While a majority of responses from both boys and girls overall reflected justice reasoning, care reasoning was used more among girls than boys. It is difficult to know, however, the extent to which the findings of these studies are specific to African American cultures given the lack of comparison samples. The same can be said about early research with either all or predominantly Caucasian samples, or samples in which ethnicity is not included as an aspect of analysis at all. A valuable direction for this area of research would be to examine moral orientation across various ethnic groups in the United States.

One study that did examine moral orientation with a cross-cultural sample was Gump et al. (2000), who assessed care and justice reasoning using hypothetical dilemmas among Mexican-American and Anglo-American college students. Mexican-Americans used significantly greater care reasoning than Anglo-Americans, however, contrary to expectations, there were no group differences in justice reasoning. The authors suggest that this difference in care reasoning may be explained in terms of the importance placed by MexicanAmericans on interpersonal connectedness and a sense of personal responsibility for the welfare of friends and family.
They also suggest that the greater emphasis on separation and individuation seen among Anglo-Americans, in contrast, would tend to de-emphasize the interpersonal connectedness and responsibility that is so crucial to care reasoning.

\section{Age and moral orientation}

The vast majority of moral reasoning research concerns moral reasoning no later than middle adulthood. The limited amount of research about moral reasoning in later life is somewhat surprising considering that Kohlberg's and Gilligan's own theoretical contributions would suggest the value of examining moral reasoning in later life. For example, although Kohlberg originally posited the completion of moral development in early adulthood, he later speculated that older age might lend itself to a seventh "soft" stage. The speculation was that this stage would involve ethical and religious thinking about existential questions such as life's meaning and would utilize a cosmic or religious perspective on life (Kohlberg \& Ryncarz, 1990). Gilligan viewed moral reasoning as being based on affective components and connected to self-concept, and hence would evolve throughout one's life (Gilligan, 1977, 1982).

One notable exception to the lack of research pertaining to moral reasoning in later life was research by Pratt et al. (1988), who examined sex differences in moral orientation (care or justice) based on real-life moral dilemmas. The subjects in this study were 12 women and 12 men each within three different age levels: $18-24$ years old, 30-45 years old, and 60-75 years old. They found that sex differences in moral orientation "appear to fluctuate across the adult life span" (p. 389). Across the entire sample, men were more likely than women to use justice-oriented responses. However, when sex differences in moral orientation were analyzed based on the age subgroups separately, they were only significant for the middleagedgroup; this subgroup accounted for the significantly greater justice-orientation among men than among women in the overall sample. It is important to note that this study had the limitation of using participant-selected real-life dilemmas. Gender differences in moral reasoning using this approach are confounded by the finding that females are more likely to select dilemmas that elicit care reasoning, while males are more likely to select dilemmas that elicit justice reasoning (Pratt et al., 1988; Walker, 1989). Although this study was also limited by a sample that was fairly homogenous with respect to ethnicity and SES, it is valuable in demonstrating the significance of examining moral reasoning at various stages of the life course, including later life.

\section{Summary and application to the current study}

The reviewed literature shows that, despite the early focus on gender differences, cultural factors such as ethnicity may be more salient to consider in understanding moral reasoning. Furthermore, the limited research pertaining to SES and older adulthood in relation to moral reasoning suggests that these, too, may be important for understanding moral reasoning. The impact of cultural factors such as ethnicity and SES is wholly unexplored in later adulthood.

This study contributes to the theoretical understanding of moral reasoning by examining moral reasoning among older 
women from diverse ethnic and SES backgrounds. It was conducted as part of a larger parent study that investigated women's views of ethical dilemmas in adult protective services (APS), the system that investigates and intervenes in cases of elder abuse and neglect. Results of the parent study are summarized in Dakin and Pearlmutter (2009). The examination of ethical dilemmas within the parent study lent itself well to the examination of older women's moral reasoning, since this area of research uses exploration of ethical dilemmas as a central methodology. Additionally, elder maltreatment dilemmas were viewed as being useful for exploring moral reasoning among older adults given the salience of this topic for this population. Furthermore, the parent study used a qualitative (focus group) design, which has been noted as a valuable, though underutilized, approach to understanding moral reasoning. For example, Humphries, Parker, and Jagers (2000) note that, "future research also might employ qualitative techniques to delve more deeply into issues of culture and moral development" (p. 62). The aim of the moral reasoning sub-study was to provide an exploratory examination of moral reasoning among a sample of ethnically and socioeconomically diverse older women based on dilemmas pertaining to elder maltreatment and APS.

\section{Methodology}

\section{Participants}

Please see Dakin and Pearlmutter (2009) for more detailed information about this study's methodology, including expanded discussion of participants, focus group locations, volunteer gatekeepers, participant recruitment, the focus group questioning route, data collection, data analysis, and establishing trustworthiness of data. Eight focus groups ranging in size from eight to 14 participants were held with 88 African American, Latina, and Caucasian women age 60 and over (see Table 1). The focus groups were homogenous with respect to ethnicity and socioeconomic status, with two focus groups with working class African American women, two with working class Latina women, two with working class Caucasian women, one with middle to upper middle SES African American women, and one with middle to upper middle SES Caucasian women. Women were specifically chosen for this study due to their relevance to APS, since the majority of APS clients are women. An additional reason for the focus group homogeneity was the methodological recommendation that focus groups be kept as homogenous as possible, particularly when discussing sensitive topics such as elder abuse (Krueger \& Casey, 2000). The SES composition of the focus groups was primarily determined through holding focus groups at sites (primarily senior centers) serving different racial/ethnic and SES communities in the metropolitan area where the study took place. The participants had no known history of abuse or neglect at the time of subject recruitment. No middle to high SES Latina group was held because of the limited Latina population in the Midwestern metropolitan area where the study took place. Participant SES was assessed via a questionnaire completed by participants prior to each focus group with questions related to education and employment background.

\section{Role of volunteer gatekeepers}

A key feature of this study's methodology was the use of volunteer gatekeepers, who were gerontological professionals and cultural insiders to the cultures represented by each focus group. Each focus group had a volunteer gatekeeper who assisted with participant recruitment and also served as assistant moderator for the focus groups (see Data collection method, described next).

\section{Data collection method}

The author served as focus group moderator for the African American and Caucasian focus groups, and the volunteer gatekeepers for these groups served as assistant moderator. The Latina focus groups were moderated by a Spanish-speaking gerontological professional. Senior center staff gatekeepers where each Latina focus group was held served as assistant moderators.

\section{Focus group questioning route}

The study's questioning route explored participants' definition of elder abuse and three dilemmas (i.e., mandatory reporting, involuntary protective services, and criminal treatment of elder abuse) within APS. Every state and territory within the United States provides APS services through federal funding mechanisms, although states vary widely from one another in terms of specific policies governing APS administration (Mixson, 2010). There has been heated debate over a variety of APS policy considerations, with much of this debate centering philosophically around the overall dilemma of whether APS policies should favor protection or freedom when these principles conflict (Dakin \& Pearlmutter, 2009). In the language of ethical theory, the word autonomy reflects the principle of freedom, while the word beneficence reflects a complex ethical principle relating to protection with three sub-principles, in the following order from most to least important: 1) one ought to prevent evil or harm; 2) one ought to remove evil or harm; and 3) one ought to do or promote good (Beauchamp \& Childress, 1989). The term paternalism is often used when discussing the freedom/ autonomy versus protection/beneficence dilemma. Paternalism is "a form of beneficence in which the helping person's concepts of benefits and harms differ from those of the client, and the helper's concepts prevail" (Abramson, 1985, p. 389).

The questioning route was developed in consultation with a researcher and the APS administrator in the metropolitan area in which the study took place. The researcher and APS administrator had previously carried out a Community Dialogue Series that examined the views of professionals in a variety of disciplines (e.g., nursing, law, medicine, social work) about six ethical dilemmas related to elder maltreatment (Anetzberger, Dayton, \& McMonagle, 1997). Participants in the Series selected these dilemmas for discussion because the participants viewed them as the most prevalent and challenging in work related to elder maltreatment. The researcher and APS administrator served as consultants throughout the current study, including consultation about using the dilemmas from the Series in the current study. The dilemmas were illustrated through scenarios that had been developed and 
Table 1

Participant Education and Most Recent Employment.

\begin{tabular}{|c|c|c|}
\hline Focus group & "What is the highest grade of education that you have completed?" & "What was your most recent employment (if any)?" \\
\hline $\begin{array}{l}\text { Working-Class Caucasian Group 1; } 8 \\
\text { participants }\end{array}$ & high school grad, 4; some college, 3; BA degree, 1 & $\begin{array}{l}\text { companion to bed-bound person, driver for nursing home residents, } 1 \text {; secretary, } \\
1 \text {; at a senior center, } 1 \text {; at an area company, } 1 \text {; for a doctor, } 1 \text {; media technician } \\
\text { at a jr. high school, } 1 \text {; for a car manufacturer, } 1 \text {; indicated "none", } 1\end{array}$ \\
\hline $\begin{array}{l}\text { Working-Class Caucasian Group 2; } 9 \\
\text { participants }\end{array}$ & $\begin{array}{l}\text { high school grad, 2; high school graduate \& legal secretary school, 1; } \\
\text { some college, 3; business school, 2; BS \& some grad school in education, } 1\end{array}$ & $\begin{array}{l}\text { research for telephone company, } 1 \text {; out of workforce a long time, } 1 \text {; teacher, } \\
1 \text {; accountant, } 1 \text {; apartment management, } 1 \text {; bus company, } 1 \text {; secretary, } 1 \text {; } \\
\text { telemarketing and secretary, } 1 \text {; receptionist/cashier/greeter, } 1\end{array}$ \\
\hline $\begin{array}{l}\text { Working class African American Group } \\
1 ; 12 \text { participants }\end{array}$ & $\begin{array}{l}\text { 11th grade, } 1 \text {; high school graduate, } 1 \text {; some college, } 6 \text {; a degree in child } \\
\text { care, } 1 \text {; extension course on bible studies, } 1 \text {; bachelor's degree, } 2\end{array}$ & $\begin{array}{l}\text { aide to sick persons, church pianist, } 1 \text {; nurse, } 2 \text {; waitress, } 1 \text {; aide, } 1 \text {; no employment } \\
\text { for } 12 \text { years, } 1 \text {; child care director, } 1 \text {; work for a company, } 1 \text {; city councilwoman, } \\
1 \text {; secretary, } 1 \text {; care giver, } 1 \text {; owned beauty shop and building shop was in, } 1\end{array}$ \\
\hline $\begin{array}{l}\text { Working class African American Group } \\
2 ; 14 \text { participants }\end{array}$ & 11th grade, 1 ; high school graduate, 4 ; some college, 9 & $\begin{array}{l}\text { work for a company, } 1 \text {; supervisor at government office, } 2 \text {; city councilwoman, } 1 \text {; } \\
\text { self-employed, } 1 \text {; hospital ombudsman, } 1 \text {; teaching assistant, } 1 \text {; licensed practical } \\
\text { nurse, } 1 \text {; work for a senior center, } 1 \text {; work for a senior meal program, } 1 \text {; none, } 4\end{array}$ \\
\hline High SES African American; 9 participants & $\begin{array}{l}\text { some college, 1; Bachelor's degree, 1; some graduate school, 1; “graduate } \\
\text { school”, 1; Master's degree, 3; Ph.D., } 2\end{array}$ & $\begin{array}{l}\text { property insurance (title) owner, } 1 \text {; librarian, } 1 \text {; college or university professor, } 2 \text {; } \\
\text { financial aid director, } 1 \text {; assistant vice president of a university, } 1 \text {; sales at a } \\
\text { department store, } 1 \text {; office manager, } 1 \text {; self-employed real estate investor, } 1\end{array}$ \\
\hline High SES Caucasian; 12 participants & $\begin{array}{l}\text { high school graduate, } 1 \text {; some college, } 1 \text {; Bachelor's degree, 2; Master's } \\
\text { degree, 6; Law degree, 1; MD, } 1\end{array}$ & $\begin{array}{l}\text { attorney, } 1 \text {; realtor } \& \text { adjunct college instructor, } 1 \text {; realtor, } 2 \text {; bank economist and } \\
\text { administrator, } 1 \text {; physician, } 1 \text {; teacher, } 2 \text {; secretary, } 1 \text {; nurse, } 1 \text {; teaching knitting, } \\
1 \text {; worked in offices \& as waitress, sold cemetery property, haven't worked in } 30 \text { years, } 1\end{array}$ \\
\hline Latino Group $1 ; 14$ participants & $\begin{array}{l}\text { no formal education, } 2 ; 2 \text { nd grade, } 2 \text {; } 3 \text { rd grade, } 2 ; 4 \text { th grade, } 2 ; 5 \text { th } \\
\text { grade, } 1 ; 7 \text { th grade, } 2 ; 8 \text { th grade, } 1 ; 9 \text { th grade, } 1 ; \text { high school grad, } 1\end{array}$ & $\begin{array}{l}\text { housewife, } 8 \text {; housekeeping, } 1 \text {; nursing assistant, } 2 \text {; homecare, } 1 \text {; cleaning, } 1 \text {; filling } \\
\text { orders for a clothing factory }\end{array}$ \\
\hline Latino Group 2; 10 participants & $\begin{array}{l}\text { no formal education, } 1 ; 2 \text { nd grade, } 3 ; 4 \text { th grade, } 1 ; 5 \text { th grade, } 1 ; 8 \text { th } \\
\text { grade, } 2 ; 9 \text { th grade } \& \text { cosmetology certificate, } 1 ; 12 \text { th grade, } 1\end{array}$ & $\begin{array}{l}\text { indicated they do not currently work*, } 3 \text {; indicated " } \mathrm{n} / \mathrm{a} \text { ", } 1 \text {; never worked in paid } \\
\text { capacity, } 1 \text {; work in a green house, } 1 \text {; in a factory, } 1 \text {; in a laundry, } 1 \text {; seamstress in a } \\
\text { factory, } 1 \text {; cosmetology, car factory, self-employed selling jewelry, } 1\end{array}$ \\
\hline
\end{tabular}


"Florence" Mandatory Reporting Scenario

Florence, a quiet, 66-year old woman, is a regular at the senior center's lunch program. She usually keeps to herself, and often seems distracted. She doesn't talk much about her home life, or about Al, her husband of forty years. Today, she seems upset, and begins crying after lunch. The senior center worker asks what is upsetting her, and Florence explains that she was shaky this morning when she forgot to take her insulin, and spilled Al's coffee. She said that he grabbed her arms and shoved her against the wall. She also talked about how he upset her, as he often does, by calling her "no good". Florence says she can't tolerate his threats and physical aggression as well as she could when they were younger. However, when she finishes crying, she firmly tells the worker that Al doesn't really mean to upset her. If fact, she says that if she could just do a better job, he wouldn't act this way. She also says that $\mathrm{Al}$ will apologize to her later, and then whispers to the worker, "Please don't tell anyone about this."

\section{"Vera" Involuntary Protective Services Scenario}

On a hot summer day, the elder abuse hotline receives a call from a police officer. Neighbors have called the police out of their concern for an 86-year old woman named Vera and her dog. Vera and her dog are dependent on the neighbors for water because the plumbing in Vera's house does not work. These neighbors have not seen Vera or her dog for several days, and are worried that she and the dog have died. The police enter the unlocked house to check on Vera. They are barely able to walk through the house because it is piled floor-to-ceiling with trash. As the police make their way through the house, they hear the angry voice of an elderly woman calling to them from the second floor, "Who is in my house? Get out!" The police proceed up the stairs, which are slippery with trash, to the second floor, where they find Vera, who seems to be dehydrated. It is obvious that there is no working toilet in the house, and that Vera and her dog are using the floor and newspapers instead. The police report the condition to the elder abuse hotline and ask whether they can hospitalize the protesting woman against her will. Social workers investigate the situation and report that although Vera is clearly unusual, she seems to be rational.

\section{"John" Criminalization Scenario}

John is a 77-year old man who lives in the attic of his daughter and son-inlaw's house. His family is living off of his social security check each month. When John's friends and other relatives try to visit him, his daughter and sonin-law send them away, saying that he is not feeling well, and doesn't want visitors. Eventually, however, when the police are called to the home for other reasons, they discover John in the attic. He is found lying in a urinesoaked blanket. The police call an ambulance that takes John to the hospital. A medical exam reveals that he is severely malnourished. A wound on his finger has been festering in a crude bandage, and his finger will have to be amputated. Although John is quite disoriented, he indicates his reluctance to have criminal charges brought against his daughter and son-in-law.

Fig. 1. Adult protective services case scenarios.

modified from actual APS situations, and they all explored the underlying tension between freedom (autonomy) and protection (beneficence) in APS work.
The questioning route had five key questions, which specifically explored participants': 1) definition of elder maltreatment; 2) views of mandatory reporting (Florence 
scenario); 3) views of involuntary protectives orders (Vera scenario); views of the criminal treatment of elder abuse (John scenario); and 5) responses to the final question, "What issues do you feel most strongly about in the stories we've discussed?" (see Fig. 1 for the questioning route's case scenarios). A pilot focus group was held with 12 older women to pre-test the questioning route. The final focus group questioning route was translated into Spanish, and the accuracy of this translation was confirmed using back-translation.

\section{APS dilemmas explored in study}

Three specific APS dilemmas were explored in this study. The first dilemma (Vera scenario) is whether elder abuse and neglect reporting should be voluntary or mandatory, a longstanding policy issue that remains controversial, despite over $90 \%$ of states now mandating reporting by specified professionals and sometimes the public generally (Anetzberger, 2005; Dakin \& Pearlmutter, 2009; Mixson, 2010). A policy mandating reporting reflects the principle of beneficence because the state is acting on behalf of a vulnerable elder or adult with a disability to assess and offer assistance. The argument against mandatory reporting reflects an appreciation for respecting clients' autonomy (Dakin \& Pearlmutter, 2009; Gilbert, 1986). Mandatory reporting laws are argued to be a violation of civil liberties, and specifically the right to informed consent, because a mandatory report of abuse or neglect denies the older or dependent adult the opportunity to accept or refuse a report and investigation (Faulkner, 1982; Gilbert, 1986).

The second ethical dilemma explored in this study concerns the provision of involuntary protective services, defined as "interventions initiated by APS social workers, without the consent of the affected adult, for the purpose of safeguarding the vulnerable adult who is at risk of abuse, neglect or exploitation" (Duke, 1997, p. 52). Involuntary protective services are courtordered services provided as a result of an investigation, and typically involve time-limited services, such as a geriatric assessment, medical treatment, or nursing home placement (Duke, 1997). It is important to note that involuntary protective services are services that the client does not want and would not receive were it not for a court order for these services. Involuntary protective services are a type of paternalistic intervention that is widely viewed as justified when the client is incapacitated, i.e., incapable of making informed and reasonable decisions. Dilemmas pertaining to involuntary protective services include whether an involuntary protective order should be pursued in "gray" cases of indeterminate or fluctuating client capacity and also what situations present enough risk to warrant involuntary intervention (Dakin \& Pearlmutter, 2009; Mixson, 2010). Issuing an involuntary protective service order in these cases would reflect deciding the dilemma in favor of beneficence, while not issuing the order would reflect deciding the dilemma in favor of autonomy.

A third policy consideration explored in this study was the criminalization of elder abuse and neglect-that is, whether elder maltreatment is more appropriately treated through social service and/or law enforcement systems. This policy consideration reflects, in part, the freedom/protection dilemma:

in the debate as to whether a victim has the right to selfdetermination in reporting a crime to law enforcement and pressing criminal charges against the perpetrator, or whether criminal prosecution should proceed if sufficient evidence exists regardless of the will of the victim (Dubble, 2006, pp. 44-45).

Elder abuse and neglect have traditionally not been viewed from a criminal lens; if cases were reported at all, they were reported to APS, which has historically handled elder abuse through a social casework model with little if any collaboration with law enforcement (Blakely \& Dolon, 2000; Dubble, 2006; Heisler, 2000; Otto, 2000). However, more recently there has been an increasing number of prosecuted elder abuse cases and a growing understanding of the criminal justice system as a valuable means for stopping abuse and neglect, protecting victims, and holding the perpetrator accountable (Heisler, 2000; Nerenberg, 2006). Approaches to enhancing the criminalization of elder abuse include increasing the collaboration between APS and law enforcement, having separate sections of state penal codes specifically dedicated to older and dependent adult abuse, and adding sentencing enhancement to crimes pertaining to elders (Blakely \& Dolon, 2000; Dubble, 2006; Heisler, 2000). Despite increasing coordination and integration between APS and law enforcement, taking a criminal justice approach to treating elder abuse continues to be controversial (Blakely \& Dolon, 2000; Brownell \& Wolden, 2002; Dakin \& Pearlmutter, 2009; Dubble, 2006). Newly passed federal legislation called the Elder Justice Act does move treatment of elder abuse further into the domain of law enforcement through an emphasis on prosecuting elder abuse (American Psychological Association, 2012; University of Southern California Davis, n.d.).

\section{Data analysis}

The focus groups were audio recorded and the recordings were then transcribed. The Spanish-speaking focus group recordings were translated into English when they were transcribed. A content analysis was performed on the transcriptions with the goal of examining within and between group responses to the dilemmas. This analysis considered areas of agreement and disagreement, and what was unsaid in addition to what was actually spoken. This analysis was also aided by extensive notes taken by the moderator and assistant moderator during each focus group, and by a methodological journal maintained by the author.

\section{Member check group}

Member checking is an important technique for establishing the trustworthiness of qualitative research, and it involves reviewing the researcher's data analysis with research participants to determine whether the researcher has represented their realities accurately (Lincoln \& Guba, 1985). A member check group session was held following completion of the initial data analysis and invitations to this event were extended to all of the participants and gatekeepers from the study's eight focus groups. Five gatekeepers from five focus groups and 28 participants from seven focus groups attended this session. The member check group participants appeared to be a representative subsample of the original study sample. The member check group participants voiced agreement that the 
Table 2

Overarching themes.

\begin{tabular}{llllllllll}
\hline & WC & WC & WC & WC & Lat & Lat & $*$ AA & $*$ Cau \\
& AA & AA & Cau & Cau & & & & \\
\hline 1) Favoring protection & $\mathrm{X}$ & $\mathrm{X}$ & $\mathrm{X}$ & $\mathrm{X}$ & $\mathrm{X}$ & $\mathrm{X}$ & $\mathrm{X}$ & $\mathrm{X}$ \\
$\begin{array}{l}\text { over autonomy } \\
\text { 3) Neighbor theme }\end{array}$ & $\mathrm{X}$ & $\mathrm{X}$ & & $\mathrm{X}$ & $\mathrm{X}$ & & $\mathrm{X}$ & $\mathrm{X}$ \\
4) Family Theme & $\mathrm{X}$ & $\mathrm{X}$ & $\mathrm{X}$ & $\mathrm{X}$ & $\mathrm{X}$ & $\mathrm{X}$ & &
\end{tabular}

Note. "AA" refers to the working class African American focus groups, "Cau" refers to the Caucasian focus groups, "Lat" refers to the Latina focus groups, *AA refers to the high socioeconomic status African American focus group, and *Cau refers to the high socioeconomic status Caucasian focus groups.

data analysis accurately reflected their understandings of elder abuse and neglect and their reactions to the case scenarios. An additional important function of the member check group was to provide a setting in which participants' moral reasoning could be explored.

\section{Results}

Reported here are overarching themes, defined as themes present across four or more of the study's eight focus groups and two or more of the questioning route's five key questions. Three overarching themes (see Table 2) from the study relate to participants' moral reasoning: 1) favoring protection over autonomy, 2) the importance of neighbors, and 3) the importance of family. Also reported here are findings from the member check group, which specifically explored their moral reasoning. Overall, these overarching themes reflect the desire to protect the individuals in the three scenarios, with this protection understood as a manifestation of caring and responsibility for one another. The overarching themes and their underlying moral reasoning are remarkably consistent with the care moral orientation.

\section{Overarching theme: favoring protection over autonomy}

In the Florence, Vera, and John scenarios, participants very clearly sided with protection-favoring mandatory reporting, involuntary protective interventions, and criminal prosecution, even though these interventions were against the wishes of the recipient in the case scenario (see Table 3 ). The Vera scenario had the most uniformity across the focus groups; all eight focus groups expressed universal and strong support for an involuntary protective services order to hospitalize Vera. The following reflects a typical participant reaction to this scenario:

$X:$ If it's [the house] in this bad of shape, I cannot understand why something can't be done socially and legally right away.
More controversial was the Florence scenario, in which participants in six of the eight focus groups favored mandated reporting to APS:

X: You have to report it. You can't let people keep doing things and not do anything about it.

Participants in the high SES Caucasian group and one of the Latina groups did not, overall, favor mandated reporting to APS. Furthermore, of the six groups with majority views favoring mandated reporting, four of these groups (one of the Latina groups and all three African American groups) had significant disagreement about this. Participants opposed to mandated reporting still felt that Florence needed to be protected and helped, but instead recommended help through informal network interventions such as the senior center worker, a minister, friends or family:

$X:$ I think the government is too often not the best way to go. Like [participant] said, start out with what they can do in the senior center maybe and provide help that way first. Then see how things progress and get her to talk more about it.

The protection theme was also apparent in the John scenario, because the majority of participants in all eight focus groups indicated the need to prosecute the case even though John himself was reluctant to do so:

$X:$ I think that the state has the right to protect seniors or people who are incompetent to help themselves. Also, these [cases] are so publicized that if one victim is kept a victim and the people get away with it, other people will be doing it.

Dissenting views opposed to prosecution were present in both of the Latina focus groups, the high SES Caucasian focus group, and one of the working class Caucasian focus groups. Most of the reluctance to prosecute involved considerations such as the desire to respect the father's wishes, the family relationship, the belief that John's children should be forgiven and given a second chance, and the view that prosecuting the children would be harmful and even abusive to the father:

$X:$ If the man Juan (John), even though he's confused, he insists that they not harm his daughter and his son-in-law, but especially his daughter, right? Well then if they do her harm, then this will end up confusing Juan even more and he will get even more sick...

Opposition to prosecution in the Latina focus groups largely reflected a strong family orientation, explored further in the importance of family overarching theme discussion. As

Table 3

Groups favoring reporting, involuntary protective services, and criminalization in the Florence, Vera and John scenarios.

\begin{tabular}{|c|c|c|c|c|c|c|c|c|}
\hline Major theme & WCAA & WCAA & WCCau & WCCau & Lat & Lat & $* A A$ & *Cau \\
\hline 1. In favor of reporting the situation to APS & $\mathrm{X}$ & $\mathrm{X}$ & $\mathrm{X}$ & $\mathrm{X}$ & & $\mathrm{X}$ & $\mathrm{X}$ & \\
\hline 1) Support for hospitalizing Vera & $\mathrm{X}$ & $\mathrm{X}$ & $\mathrm{X}$ & $\mathrm{X}$ & $\mathrm{X}$ & $\mathrm{X}$ & $\mathrm{X}$ & $\mathrm{X}$ \\
\hline 1) Majority in favor of prosecution & $\mathrm{X}$ & $\mathrm{X}$ & $\mathrm{X}$ & $\mathrm{X}$ & $\mathrm{X}$ & $\mathrm{X}$ & $\mathrm{X}$ & $\mathrm{X}$ \\
\hline
\end{tabular}

Note. "AA" refers to the working class African American focus groups, "Cau" refers to the Caucasian focus groups, "Lat" refers to the Latina focus groups, *AA refers to the high socioeconomic status African American focus group, and *Cau refers to the high socioeconomic status Caucasian focus groups. 
in the Florence (mandatory reporting) scenario, even those participants who did not support the formal intervention (prosecution) still insisted on the need for John to receive a protective intervention of some kind:

Moderator: Okay, so once Juan has been treated and he's a little better, and he's already - and they ask him the question of whether he wants to press charges, and he says no. Now he's no longer confused, and his mind is clearer, but Juan doesn't want to press charges against his daughter. So then, what do you think should happen?

$X$ : I think that no, if that's what he says, if he says what he thinks then

$X:$ If he doesn't want it -

$X$ : But then neither should he keep living with his daughter. They should look for another place, or another person to care for him.

An emphasis on protection was also apparent among participants within several groups in response to the final, summarizing question, "What issues do you feel most strongly about in the stories we've discussed?" For example, one participant responding to this question stated that the individuals in all three scenarios needed help:

X: Well, I guess what I'm trying to say here is, yeah, these people, like somebody said here. They all needed help, but didn't know that they needed it. If you don't know you don't know...

Another participant even uses the language of protection in responding to this question:

\section{$X:$ They need to be protected and educated.}

A somewhat more balanced view on the issue of protection and freedom was evident in the high SES focus groups. Although these groups, like the other groups, favored protection in their response to the scenarios, they also indicated a philosophical appreciation for autonomy. The high SES Caucasian group was one of only two groups that did not favor reporting to APS in the Florence scenario, and the high SES African American group was one of the focus groups with a dissenting minority of participants opposed to this intervention. In addition, both high SES groups indicated an appreciation for the principle of autonomy in their discussions of the Vera scenario, even though they strongly favored protection through court-ordered hospitalization in this case. When they considered the final question, "What issues do you feel most strongly about in the stories we've discussed?", participants in the high SES African American focus group stated that the issues in the scenarios were too complex to recommend either freedom or protection. As one participant stated:

$X:$ And these are all complex situations, and an either/or doesn't work for me - in any of these cases. They all require much more complex ... I just always kind of object to the way that we feel that we always have to be for us or against us. And it's too complex, life is too complex, and these are new questions cause we're living longer, and they're becoming even more complex.
Furthermore, they suggested that the United States leans so heavily towards respecting freedom that it often overlooks protection when it is warranted.

$X$ : Our society is generally so focused on the rights of the individual that autonomy, no matter what, and that may not be the appropriate response.

Thus, the high SES groups' responses to the Florence, Vera, and John scenarios were less concerned with favoring protection unilaterally than they were about bringing freedom and protection into a greater balance. The somewhat greater emphasis on justice versus care reasoning seen in the high SES focus groups is consistent with findings by Miller et al. (1990), who reported a greater orientation towards autonomy and individualism among middle class versus lower class subjects from India. Potentially noteworthy were opinions against mandated reporting and prosecution in the Latina focus groups, and the lack of dissenting opinions about prosecution among the African American participants in response to the John scenario.

\section{Overarching theme: the importance of neighbors}

The second overarching theme relevant to understanding the participants' moral reasoning was the theme, the importance of neighbors, which emphasizes people's responsibility for looking out for and helping one another. This and the importance of family (discussed next) overarching themes both emphasize informal network (e.g., neighbors, friends, family, faith community) interventions that were recommended in addition to or instead of formal network interventions (mandated reporting, involuntary protective services, criminalization). These themes also both promoted protection in emphasizing people's responsibility to care for and protect those in their informal network (e.g., friends, neighbors, family). The neighbor theme was mentioned within six focus groups and occurred within discussions about Vera and John, as well as in the final question. The neighbor theme was particularly prominent in the Vera discussion. Along with expressing the need for mutual responsibility and care among friends and neighbors, participants also expressed criticism that none of Vera's neighbors had stepped in to help her:

$X:$ Might also wonder about the neighbors for letting this go on, I mean I don't know what the neighbors can do, but it would seem to me, if I had an elderly neighbor who was coming to me for water, ah, I would try to do something. Long before things got to this stage.

The neighbor theme was expressed powerfully by one participant as a response to the final, summarizing question:

$X$ : And the ones of us that are still able to function, well I guess we have an obligation to the ones that don't.

One working class Caucasian group and one Latina group did not highlight this theme. Thus, this theme was present across ethnicity and socioeconomic status categories, and was perhaps particularly prominent within the African American focus groups and the high SES focus groups, all of which endorsed this theme. 
Overarching theme: the importance of family

The third overarching theme to shed light on participants' moral reasoning was the importance of family. This theme, indicating the responsibility of family members for intervening in elder maltreatment situations, was present across the definitional question, all of the scenarios, and the final, summarizing question. As in the neighbor theme, an emphasis on protection was also implicit in the family theme. The family theme was of particular importance within the Latina focus groups and was present across all the questions discussed in these groups. The Latina focus groups considered the scenarios from the perspective of preserving the entire family unit to a greater degree than did the non-Latina groups, which considered the scenarios almost entirely from the perspective of the victim's well-being. Still, the majority of the Latina focus group participants did hold the victim's well-being as their primary consideration.

The Latina participants' comments about Vera particularly highlighted their strong belief that family members have a responsibility to care for their older relatives:

$X:$... call the family and let the family know that they need to take her out and take her somewhere. To look for treatment.

In the final, summarizing question, a participant from one of the Latina focus groups described why the Vera scenario was the most significant of the three scenarios:

$X:$ My opinion was that she was there with the dog, she didn't have anyone to take care of her, no relatives or anyone.

One of the possible interventions discussed in the Florence scenario was that someone such as the senior center worker, a psychologist, APS worker, or a minister should counsel both Florence and Al together. This suggestion was raised within both of the Latina focus groups, one of the working class African American focus groups, and one of the working class Caucasian focus groups, however the nature of this recommendation differed between the Latina and non-Latina focus groups. Specifically, in the African American and Caucasian groups, the recommendation of counseling Florence and Al together reflected the desire to protect Florence, rather than to preserve their marriage. In contrast, in the Latina groups, this recommendation reflected their strong feelings about the importance of preserving marriage.

Differences between the Latina and non-Latina focus groups were also apparent in discussions about the John scenario. Like the other six focus groups, the two Latina focus groups favored prosecuting the daughter and son-in-law in the John scenario. However, both of the Latina focus groups had dissenting participants opposed to prosecution, as did one of the working class Caucasian focus groups and the high SES Caucasian focus groups. A participant in one of the Latina focus groups stated:

$X$ : If the man Juan (John), even though he's confused, he insists that they not harm his daughter-and his son-in-law, but especially his daughter, right? Well then if they do her harm, then this will end up confusing Juan even more and he will get even more sick...
The reservations about prosecution seen in the Latina groups are consistent with these groups' greater emphasis on interventions meant to involve and preserve the family. The Latina focus groups similarly stood out from the non-Latina focus groups in the six focus groups that discussed incarceration as a sentencing option (one of the working class Caucasian focus groups and the high SES Caucasian focus group did not discuss incarceration). Participants in five focus groups favored incarceration for both the daughter and son-in-law, while one focus group (one of the working class Caucasian focus groups) favored incarceration for the son-in-law only, and some other sentencing option for the daughter. All five of the groups with majority opinions favoring incarcerating both the daughter and son-in-law also had dissenting opinions opposing incarceration, however the dissenting Latina and non-Latina focus groups differed in their reasons for opposing incarceration. The dissenting African American and Caucasian focus group participants opposed incarceration due to considerations such as the desire to protect John by sparing him pain or the belief that incarceration is ineffective in terms of rehabilitation. In contrast, the dissenting Latina focus group participants opposed incarceration due to the desire to preserve the family unit, and they provided alternate recommendations such as giving the daughter and son-in-law another chance to care for John, or even court ordering the daughter to care for John. It is noteworthy that a discussion about the role of family in responding to abuse and neglect was totally absent from the high SES focus groups.

\section{Member check group's exploration of moral reasoning}

Altogether, the overarching themes and their underlying moral reasoning explored in the member check group are remarkably consistent with the care orientation. The protection, neighbor, and family overarching themes emphasized protection as a manifestation of caring and responsibility for one another. Participants in the member check group stated that they could identify with the people described in the scenarios because the participants themselves were older people, which heightened their sense that intervention was urgently needed in these cases. This identification created an ethic of care in which interventions to help those in need were perceived as a form of caring. Implicit within this ethic of care was that the focus group participants themselves may also one day need assistance and care from others. As one participant stated during the member check group:

\section{$X:$ I want to be valued, and I am worth intervening for.}

This connects with earlier discussions during the focus groups, when participants described being especially concerned with the John scenario because they could imagine themselves in the role of the victim.

$X$ : [This case] could have been either one of us. I mean because he was taking care of himself up to whatever point put him up in the attic. And we're all coming here to the center and people are helping look out after us. But suppose for some reason the senility set in. Either one of us could be that person in the attic. 
When participants strongly identified with the individuals depicted in the case scenarios, the failure to intervene was perceived as not caring for or valuing these individuals, rather than as preserving their autonomy.

Ward (1995) proposed an ethic of care, and characteristics of care, compassion, and interdependence as core cultural values in African American communities. While the care orientation was certainly present among the African American participants in the current study, it was not limited to these participants, and also was present among the Latina and Caucasian participants. Pratt et al. (1988) found that older women used care and justice reasoning equally, whereas the older women in the current study favored care reasoning. The greater use of care reasoning within the current study could reflect its greater SES and ethnic heterogeneity, in comparison with the homogenous (middle class and presumably primarily Caucasian) sample in the Pratt et al.'s (1988) study.

The member check group also revealed that participants favored protection in the three scenarios because an exclusive emphasis on autonomy was viewed as being an inappropriate response to some of the more extreme problems of elder maltreatment. For instance, when participants in the member check group were asked why they had favored protection (beneficence) over freedom (autonomy) in responding to the case scenarios, they stated that the emphasis on the freedom value was what led to Florence, Vera, and John's current situations. This view mirrored earlier statements within the high SES African American focus group that autonomy is tremendously overemphasized in our country-in other words that freedom and protection are out of balance with one another in this country. Expressed frequently during the focus groups was the view that overemphasizing autonomy will cause problems to escalate out of control before intervention is allowed. Intervening quickly when problems arise, and before these problems become catastrophes, was seen by the participants as being a preferable and less painful alternative.

The strong apparent care orientation seen among participants in this study seems potentially at odds with Miller and Bersoff's (1992) finding that subjects from the United States prioritized justice considerations, whereas subjects from India prioritized interpersonal considerations. This apparent difference in findings could be attributable to participant differences between the two studies. In comparison with the participants in the current study, the participants in the Miller and Bersoff study were both males and females, younger, higher SES, and presumably primarily Caucasian (results do not report on ethnicity). The suggestion that care reasoning may be a feature of subordinate social status (Tronto, 1987) is consistent with its predominance with the current study's participants, the majority of whom were working class and ethnic minorities. Further supporting this idea is the greater appreciation of autonomy (part of the justice orientation) among the current study's high SES participants, which is consistent with these participants' greater privilege and elevated social status, perhaps making them more similar to the American participants in Miller and Bersoff's study.

The strength of the family theme among the Latina participants somewhat reduced the protection theme within these groups in that some Latina participants prioritized family preservation over individual protection. However, this does not necessarily reflect a reduction in the care orientation in these groups. This is because the Latina groups strongly emphasized the responsibility of family members for one another, and interpersonal responsibility is a core component of the care orientation. For example, the suggestion in the John scenarios that the daughter be court-ordered to care for her father reflects a strongly interpersonally and relationally-based morality, which is consistent with the care orientation's emphasis on interpersonal considerations of caring and interpersonal responsibility. Thus, it seems that Latina participants still expressed the care orientation, although the expression of this orientation may have been subtly different than in the other groups. While Gump et al. (2000), found a greater use of care reasoning among Mexican-American than Anglo-American college students, care reasoning predominated across all three ethnic groups within the current study. Perhaps this difference in findings is due to different participant ages between the two studies.

\section{Discussion}

\section{Limitations}

As an exploratory study, this research had a variety of limitations. Its convenience sample presented a possible selection bias. Specifically, the majority of the focus group participants were engaged in a variety of civic organizations (e.g., senior centers and churches) from which they were recruited. Because the participants were socially active and engaged, they may have had more favorable views towards protective interventions than did people who did not have this kind of engagement in community organizations and services. A second limitation is the lack of age and gender comparison groups. Older women's emphasis on protection and care in responding to these case scenarios does not necessarily mean that they would emphasize these more than men or younger subjects in responding to the same scenarios.

A third limitation concerns the scenarios themselves. It is unclear whether the care orientation seen in the participants' responses to the three scenarios would be elicited in response to other scenarios. For example, given the importance of family overarching theme, the fact that two of the three dilemmas concerned maltreatment by family members may have added complexity to the participants' moral reasoning. It is also unclear whether the care orientation would have been evoked in scenarios involving less severe forms of abuse. The lack of variation or gradation in the scenarios means that the specific aspect of the scenarios eliciting the care orientation in these participants is unknown. In addition, Vera was the oldest of the case scenarios and discussion of this case yielded the strongest, most unanimous emphasis on protection. It is possible that Vera's advanced age contributed to participants strongly favoring protection in responding to this scenario.

\section{Directions for future research}

To extend this line of research and address the limitations noted above, it would be important to include older men and younger adults in future research. The variations in care 
reasoning identified in this study based on SES and ethnicity underscore the salience of these characteristics, and they therefore should continue to be included. Future research should present different versions of each scenario with varying types of perpetrators, such as relatives, friends, strangers, and employees (e.g., a nursing home staff perpetrating abuse). This would provide further insight into the domains in which care versus justice reasoning is elicited in different types of interpersonal relationships. Future research could also present different versions of each scenario with varying victim ages to explore how victim age may impact the dynamics of care versus justice reasoning. Additionally, presenting several versions of each scenario with varying levels of severity could be helpful for exploring the tipping points at which participants begin to favor beneficence or autonomy in responding to the scenarios. Examining the range of subject characteristics and case scenarios as suggested here would require a quantitative, experimental approach and large sample. A precedent for such an approach may be seen in Miller and Bersoff's (1992) research examining Indian and American adults' and children's moral reasoning around dilemmas involving conflict between justice and interpersonal (i.e., care orientation) considerations. Participants in this research were randomly assigned to respond to dilemmas with varying levels of severity.

A particular advantage of qualitative approaches is their ability to inductively generate knowledge. Related to this, an important purpose of this study's member check group was to identify the underlying reasons for participants' moral reasoning in response to the three dilemmas. The participants indicated that one of the primary reasons for their care orientation was their identification with individuals described in the case scenarios. This yields the hypothesis that perhaps one's similarity to a maltreated individual in a case scenario is an important factor in eliciting a care orientation. If this were the case, we would predict that older adults as a group would have a stronger care orientation in response to elder maltreatment scenarios than would younger adults. If we had both male and female subjects, we would also predict age to be more important than gender in terms of eliciting a care orientation. As far as we know, this hypothesis has never been explored previously, and could prove a ripe topic for future inquiry.

\section{Conclusion}

This exploratory study was the first to examine moral reasoning among ethnically and socioeconomically diverse women in later life. The nearly total absence of scholarly inquiry into moral reasoning at this stage in life seems to reflect the implicitly ageist assumption that meaningful development only occurs in the first half of life. The emphasis on protection seen among the participants in this study strongly reflects the care orientation. Furthermore, the subtle variations in care orientation based on ethnicity and SES highlight the salience of these variables in understanding moral reasoning. Future research with the greater variation in subjects and case scenarios as suggested here would allow for a more complete exploration of moral reasoning. Continued examination of moral reasoning among older adults furthers a lifespan approach to human development research. Considering the limited research in this area, this is a sorely needed area for inquiry.

\section{Acknowledgments}

The author would like to acknowledge and thank the participants in this study for their efforts; the reviewers of this manuscript for their valuable contributions; Dr. Sue Pearlmutter for her guidance; Dr. Nicole Cesnales, Dr. Jim Dakin, and Kristin Gossett for their assistance with manuscript preparation; and the Cleveland Consortium Against Adult Abuse for their financial support of the research.

\section{References}

Abramson, M. (1985). The autonomy-paternalism dilemma in social work practice. Social Casework, 66(7), 387-393.

American Psychological Association (2012). The Elder Justice Act (S. 1070/H.R. 1783). Retrieved from: http://www.apa.org/about/gr/issues/aging/elderjustice-facts.aspx

Anetzberger, G. J. (2005). Clinical management of elder abuse: General considerations. In G. J. Anetzberger (Ed.), The clinical management of elder abuse (pp. 27-41). Binghamton, NY: Haworth Press.

Anetzberger, G. J., Dayton, C., \& McMonagle, P. (1997). A community dialogue series on ethics and elder abuse: Guidelines for decision-making. Journal of elder abuse \&' neglect, 9(1), 33-50.

Auerbach, J., Blum, L., Smith, V., \& Williams, C. (1985). On Gilligan's "in a different voice". Feminist Studies, 11(1), 149-161.

Beauchamp, T. L., \& Childress, J. F. (1989). Principles of biomedical ethics. New York: Oxford University Press.

Blakely, B., \& Dolon, R. (2000). Perceptions of APS workers of the support provided by criminal justice professionals in a case of elder abuse. Journal of elder abuse and neglect, 12(3/4), 71-94.

Broughton, J. M. (1983). Women's rationality and men's virtues: A critique of the gender dualism in Gilligan's theory of moral development. Social Research, 50(3), 597-642.

Brownell, P., \& Wolden, A. (2002). Elder abuse investigation strategies: Social services or criminal justice? Journal of Gerontological Social Work, $40(1 / 2), 83-100$

Contratto, S. (1994). V. A too hasty marriage: Gilligan's developmental theory and its application to feminist clinical practice. Feminism $\mathcal{\sigma}$ Psychology, 4(3), 367-377.

Dakin, E., \& Pearlmutter, R. S. (2009). Older women's perceptions of ethical dilemmas in adult protective services: A cross-cultural, exploratory study. Journal of elder abuse and neglect, 21(1), 15-57.

Dubble, C. (2006). A policy perspective on elder justice through APS and law enforcement collaboration. Journal of Gerontological Social Work, 46(3/4), 35-55.

Duke, J. (1997). National study of involuntary protective services to adult protective services clients. Journal of elder abuse and neglect, 9(1), 51-68.

Faulkner, L. R. (1982). Mandating the reporting of suspected cases of elder abuse: An inappropriate, ineffective, and ageist response to the abuse of older adults. Family Law Quarterly, 16(1), 64-91.

Gibbs, J. C., Basinger, K. S., \& Fuller, D. (1992). Moral maturity: Measuring the development of sociomoral reflection. Hillsdale, New Jersey: L. Erlbaum Associates.

Gilbert, D. A. (1986). Ethics of mandatory elder abuse reporting statutes. Advances in Nursing Science, 8(2), 51-62.

Gilligan, C. (1977). In a different voice: Women's conceptions of self and of morality. Harvard Educational Review, 47(4), 481-517.

Gilligan, C. (1982). New maps of development: New visions of maturity. American Journal of Orthopsychiatry, 52(2), 199-212.

Gilligan, C., \& Attanucci, J. (1988). Two moral orientations: Gender differences and similarities. Merrill-Palmer Quarterly, 34(3), 223-237.

Gump, L. S., Baker, R. C., \& Roll, S. (2000). Cultural and gender differences in moral judgment: A study of Mexican Americans and Anglo-Americans. Hispanic Journal of Behavioral Sciences, 22(78), 78-93.

Heisler, C. J. (2000). Elder abuse and the criminal justice system: New awareness, new responses. Generations, 24(2), 52-58.

Humphries, M. L., Parker, B. L., \& Jagers, R. J. (2000). Predictors of moral reasoning among African American children: A preliminary study. Journal of Black Psychology, 26(1), 51-64

Jagers, R. J., \& Mock, L. O. (1993). Culture and social outcomes among inner-city African American children: An afrographic exploration. Journal of Black Psychology, 19(4), 391-405. 
Kerber, L. K. (1986). Some cautionary words for historians. Signs, 11(2), 304-310.

Kohlberg, L. (1973). Stages and aging in moral development: Some speculations. Gerontologist, 13(4), 497-502.

Kohlberg, L., \& Hersh, R. H. (1977). Moral development: A review of the theory. Theory Into Practice, 16(2), 53-59.

Kohlberg, L., \& Ryncarz, R. A. (1990). Beyond justice reasoning: Moral development and consideration of a seventh stage. In C. N. Alexander, \& E. J. Langer (Eds.), Higher stages of human development: Perspectives on adult growth (pp. 191-207). London: Oxford University Press.

Krueger, R. A., \& Casey, M. A. (2000). Focus groups: A practical guide for applied research (3rd ed.). Thousand Oaks, CA: Sage.

Levine, C., Kohlberg, L., \& Hewer, A. (1985). The current formulation of Kohlberg's theory and a response to critics. Human Development, 28(2), 94-100.

Lincoln, Y. S., \& Guba, E. G. (1985). Naturalistic inquiry. Beverly Hills, CA: Sage.

Lyons, N. P. (1983). Two perspectives: On self, relationships, and morality. Harvard Educational Review, 53(2), 125-144.

Maqsud, M. (1980). Relationships between personal control, moral reasoning, and socioeconomic status of Nigerian Hausa adolescents. Journal of Youth and Adolescence, 9(4), 281-288.

Miller, J. G., \& Bersoff, D. M. (1992). Culture and moral judgment: How are conflicts between justice and interpersonal responsibilities resolved? Journal of Personality and Social Psychology, 62(4), 541-554.

Miller, J. G., Bersoff, D. M., \& Harwood, R. L. (1990). Journal of Personality and Social Psychology, 58(1), 33-47.

Mixson, P. M. (2010). Public policy, elder abuse, and adult protective services: The struggle for coherence. Journal of elder abuse and neglect, 22(1-2), 16-36.

Murphy, J. M., \& Gilligan, C. (1980). Moral development in late adolescence and adulthood: A critique and reconstruction of Kohlberg's theory. Human Development, 23(2), 77-104.

Nails, D. (1983). Social-scientific sexism: Gilligan's mismeasure of man. Social Research, 50(3), 643-664.

Nerenberg, L. (2006). Communities respond to elder abuse. Journal of Gerontological Social Work, 46(3/4), 5-33.

Nicholson, L. J. (1983). Women, morality, and history. Social Research, 50(3), 514-536.
Otto, J. M. (2000). The role of adult protective services in addressing abuse. Generations, 24(2), 33-38.

Pratt, M. W., Golding, G., Hunter, W., \& Sampson, R. (1988). Sex differences in adult moral orientations. Journal of Personality, 56, 373-391.

Reimer, J., Paolitto, D. P., \& Hersh, R. H. (1990). Promoting moral growth from Piaget to Kohlberg. Prospect heights (2nd ed.). Illinois: Waveland Press, Inc.

Smetana, J. G., Killen, M., \& Turiel, E. (1991). Children's reasoning about interpersonal and moral conflicts. Child Development, 62(3), 629-644.

Sommers, C. H. (1995). Pathological social science: Carol Gilligan and the incredible shrinking girl. Annals of the New York Academy of Sciences, 775(1), 369-381.

Tronto, J. C. (1987). Gender difference to a theory of care. Signs, 12(4), 644-663.

University of Southern California Davis School of Gerontology (n.d). What is the Elder Justice Act? Retrieved from: http://gerontology.usc.edu/newsresources/news/what-is-the-elder-justice-act/

Walker, L. J. (1984). Sex differences in the development of moral reasoning: A critical review. Child Development, 55(3), 677-691.

Walker, L. J. (1989). A longitudinal study of moral reasoning. Child Development, 60(1), 157-166.

Ward, J. V. (1995). Cultivating a morality of care in African American adolescents: A culture-based model of violence prevention. Harvard Educational Review, 65(2), 175-188.

Weisz, A. N., \& Black, B. M. (2002). Gender and moral reasoning: African American youths respond to dating dilemmas. Journal of Human Behavior in the Social Environment, 6(3), 17-34.

Wilson, F. L. (1995). The effects of age, gender and ethnic/cultural background on moral reasoning. Journal of Social Behavior and Personality, 10(1), 67-78.

Woods, L. N., \& Jagers, R. J. (2003). Are cultural values predictors of moral reasoning in African American adolescents? Journal of Black Psychology, 29(1), 102-118.

Zeidner, M., \& Nevo, B. (1987). The cross-cultural generalizability of moral reasoning research: Some Israeli data. International Journal of Psychology, $22,315-330$. 